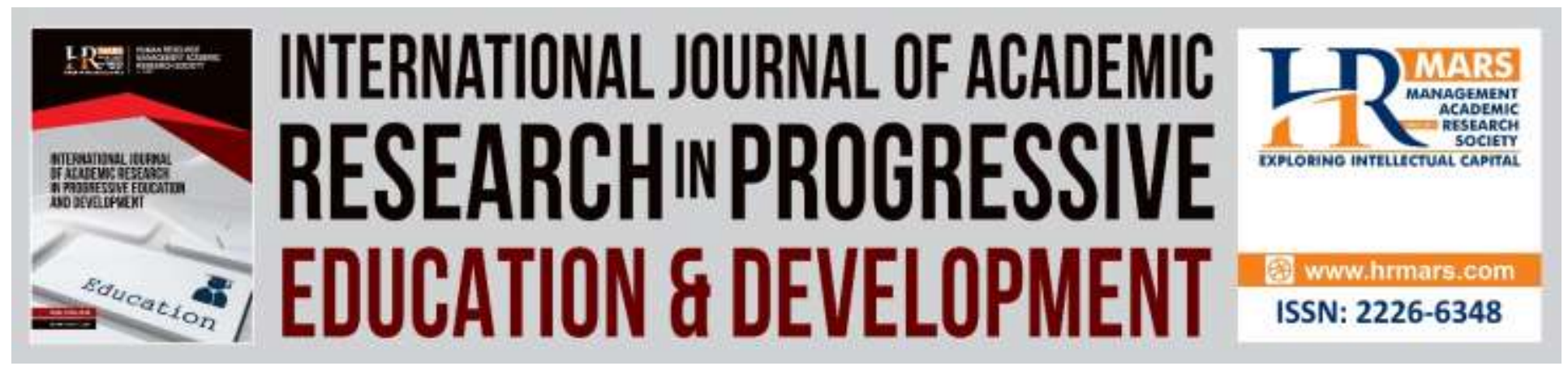

\title{
Improving Undergraduate Students' Positive affect through Mindful Art Therapy
}

\author{
Ha Ming Hui \& Aini Marina Ma'rof
}

To Link this Article: http://dx.doi.org/10.6007/IJARPED/v8-i4/6698

DOI:10.6007/IJARPED/v8-i4/6698

Received: 14 October 2019, Revised: 29 October 2019, Accepted: 15 November 2019

Published Online: 30 November 2019

In-Text Citation: (Hui, \& Ma'rof, 2019)

To Cite this Article: Hui, H. M., \& Ma'rof, A. M. (2019). Improving Undergraduate Students' Positive Affect through Mindful Art Therapy. International Journal of Academic Research in Progressive Education and Development, 8(4), 757-777.

Copyright: (C) 2019 The Author(s)

Published by Human Resource Management Academic Research Society (www.hrmars.com)

This article is published under the Creative Commons Attribution (CC BY 4.0) license. Anyone may reproduce, distribute, translate and create derivative works of this article (for both commercial and non-commercial purposes), subject to full attribution to the original publication and authors. The full terms of this license may be seen at: http://creativecommons.org/licences/by/4.0/legalcode

Vol. 8(4) 2019, Pg. 757 - 777

http://hrmars.com/index.php/pages/detail/IJARPED JOURNAL HOMEPAGE

Full Terms \& Conditions of access and use can be found at http://hrmars.com/index.php/pages/detail/publication-ethics 


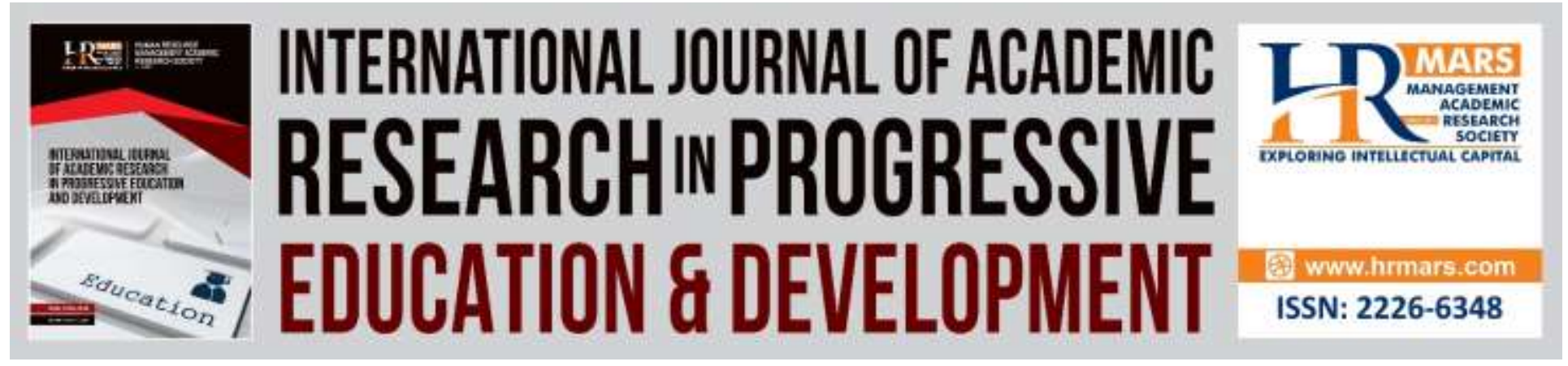

\title{
Improving Undergraduate Students' Positive Affect through Mindful Art Therapy
}

\author{
Ha Ming Hui \& Aini Marina Ma'rof
}

Faculty of Educational Studies, Universiti Putra Malaysia, 43400 UPM Serdang, Malaysia

\begin{abstract}
With the increasing popularity of positive psychology, current studies are more concerned in promoting mental health rather than only focusing on pathological disorders. Hence, the term "subjective well-being" was introduced as a pertinent area of study where new research has emerged regarding its components: positive affect, negative affect and life satisfaction. The current study serves as a preliminary study within the Malaysian higher education context with the aim to examine the impact of a relatively new approach to mindful art therapy, Zentangle ${ }^{\circledR}$, on improving the subjective well-being of first year teacher trainee students in a Malaysian public university in terms of positive affect. This study adopted the one-group pretest posttest design in which 44 students participated in the study. Participants were required to answer two sets of questionnaires before and after the Zentangle ${ }^{\circledR}$ intervention. Through descriptive and inferential analyses of data obtained, this study found that the level of positive affect was not significantly correlated with stress level. In addition, the most important finding in this study was level of subjective well-being in terms of positive affect significantly increased after participants' experience with mindful art therapy. This study serves as the first, or one of the first to study on Zentangle ${ }^{\circledR}$ in the Malaysian context and aims to provide insights on mindful art therapy and positive affect, probing future studies looking into related topics.
\end{abstract}

Keywords: Subjective Well-Being, Positive Affect, Mindful Art Therapy, Zentangle ${ }^{\circledR}$

\section{Introduction}

Historically, psychological studies have focused substantially on modulating negative feelings and its impact on psychopathology. However, the absence of the psychological problem or negative emotion does not indicate mental well-being. Seligman and Csikszentmihalyi (2000) pointed out that simply focusing on problems of those who suffered from maladaption of life is not enough, as most people seek advice to achieve a more flourishing and optimal life. Therefore, they suggest psychologists to not only pay attention on repairing the worst things in life but should also broaden their vision to also build positive qualities. From then on, positive psychology, which was staked out by Martin Seligman as a distinct sub-domain of psychology in 1988 (Park, 2015), emerged. Psychologists started paying more attention to positive development and well-being beyond the preceding imbalanced focus on negative developmental 
outcomes. Among various positive human developmental outcomes, the study of subjective wellbeing (SWB) is highly concerned (Yap, 2015).

Diener was the first researcher who introduced the term SWB in year 1984. It has been depicted as evaluations of one's life, encompassing both affective reactions and cognitive judgments (Diener, 2000; Kesebir \& Diener, 2008). SWB is associated with the term 'mental health' (Aziz, 2016). The term 'mental health' is distinctively different from term 'mental illness'. Mental illness is referred as a deficit where maladjustment of mood, thought and/or behaviour takes place (Carl et al., 2013). Mental illness is absent in mental health. Mental health is a state in which one is being completely well in the sense of emotional, psychological and social, and mental illness is absent in this state (Keyes, 2005). SWB is composed of three major components: positive affect (PA), negative affect (NA) and life satisfaction (LS) (Andrews \& Withey, 1976). These components are correlated, yet they are independent constructs that should be measured separately. The presence of positive affect does not signify the absence of negative affect and vice versa.

Positive affect (PA), as one of the components of SWB, refers to the experience of positive emotions that "reflect a level of pleasurable engagement with the environment, such as happiness, joy, excitement, enthusiasm, and contentment" (Clark, Watson \& Leeka, 1989; Pressman \& Cohen, 2005). Numerous studies examining PA have found that it is beneficial in relation to stress, including improving physical health and psychological functioning. It also correlates with successful outcomes (Zhang \& Han, 2016; Ashby, Isen \& Turken, 1999; Cohn et al., 2009; Fredrickson \& Joiner, 2002; Okely, Weiss \& Gale, 2017; Lyubomirsky, King \& Diener, 2005). PA has also been found to be positively associated with rational coping (Waters, 2015), and help in improving the ability to search for alternative options in task completing missions (Fredrickson, 2001). PA strengthens intimate interpersonal relationships (Hoppmann et al., 2011) and reduces symptoms of depression (Meeks, Shah, \& Ramsey, 2009), aggressive behaviors, high blood pressure, and increased heart rate (Zellars et al., 2009).

The World Health Organization (WHO) constitution defines health as "a state of complete physical, mental and social well-being and not merely the absence of disease or infirmity" (World Health Organization, 2018). In other words, an individual is considered healthy only when he is well physically and mentally. Mental health is the requisite and vital component of health. However, mental health problems have been increasing over the years and became a public health problem globally (Kesler et al., 2015). Mental health problems are among the most burdensome in the world, and it is estimated that mental health problems will increase over the next four decades (Bruffaerts et al., 2015).

According to National Institute of Mental Health (NIMH), there are approximately 1 in 6 adults aged 18 or older in the United States that have a mental health condition in 2016. In England, 1 in 6 adults aged 16 to 64 had a common mental disorder in 2014 (McManus, Bebbington, Jenkins \& Brugha, 2016). According to WHO European region, in Norway, Iceland, European Union countries and Switzerland, 27\% of the adults ages 18 to 65 suffered from at least one of a series of mental disorders. While in Asia Pacific region, estimated $6 \%$ of the adult population in Indonesia has mental disorders in 2013 (ASEAN, 2016). WHO reported around 9.2\% of the global burden of diseases in Myanmar (ASEAN, 2016) and 14.4\% in Philippines were contributed by neuropsychiatric disorders in year 2008 (Mental Health Atlas, 2011). The 
Singapore Mental Health Study 2010 reported approximately 12\%, which is 1 in 8 of the resident population ages 18 and above suffer from mental disorder (Chong et al., 2017). Mental health is a critical issue in Malaysia too. National Health and Morbidity Survey (NHMS) statistics in 2015 showed that the prevalence of mental health issues among adults at age 16 years and above, increased from $10.7 \%$ in 1996 to $29.2 \%$ in 2015.

Mental health problems are steadily growing and becoming a public health issue globally. There are numerous interventions to improve mental health of individuals or to treat mental illnesses. Among them, art therapy gained increasing focus over the past decade (Springham, 2012). The implementation of art therapy involves the use of art media, creative process and resulting art product in regulating emotions and cognition as well as enriching overall health (American Art Therapy Association, 2016; Drake, Coleman \& Winner, 2011; Pendleton, 1999; Wilkinson \& Chilton, 2013). Visual art therapies can be categorized into two types, art-in-therapy and art-as-therapy (Losinski, Hughey \& Maag, 2016). The distinct difference between them is that art-in-therapy is conducted by a psychotherapist with license, while art-as-therapy is the therapeutic effects when one is creating art, without the interpretation or participation of a licensed therapist (Walsh et al., 2005; Foster, 1992). One of the increasingly effective mindful artas-therapy interventions is Zentangle ${ }^{\circledR}$.

Zentangle ${ }^{\circledR}$ is an easy-to-use mindful art therapy created by Rick Roberts and Maria Thomas in 2003. It involves repetitively creating patterns in a structured way, encompassing the principle of one stroke at one time. Materials needed to practice Zentangle ${ }^{\circledR}$ in a traditional way include a 31/2 inch square tile made of special paper, a black pen and a pencil (Malchiodi, 2014). It does not require a lot of equipment, space or technical ability to draw Zentangle ${ }^{\circledR}$. There is no right or wrong while drawing Zentangle ${ }^{\circledR}$, thus art talent is not needed in this activity. Rather than focusing on the product, Zentangle ${ }^{\circledR}$ emphasizes on the process (The Brunswick News, 2014). Studies show that Zentangle ${ }^{\circledR}$ produces many benefits including increases mental retention, stimulates new perspectives and creativity, improves one's mood, instill a sense of selfconfidence, helps in relaxation and self-soothing, and can be used as a tool for anger management (Malchiodi, 2014; The Brunswick News, 2014; Krahula, 2012).

Mindful art therapy shows beneficial effects on a variety of outcomes. One of the advantages highlighted was the promotion of resilience and well-being. According to Monti and colleagues (2006; 2012) and Peterson (2015), mindful art therapy aid in decreasing distress and anxiety, as well as other dysregulated emotions. Jang, Kang, Lee and Lee (2016) also reported decreased level of depression in cancer patients after implementing mindful art therapy.

Not many researchers studied specifically on the impact of mindful art therapy and positive affect. Existing research found the effectiveness of visual art-making on affects (negative and positive) and perceived self-efficacy. The result of this study showed that art-making significantly increased positive affect of the participants (Kaimal \& Ray, 2017).

Besides, in the study of Pogrebtsova and colleagues (2017), although a 5 days long positive reappraisal practice did not significantly increase positive affect in respondents, but significant result shown in higher mean level of daily positive affect when participants practised appraisal combined with mindfulness, compared to reappraisal-only. This suggested integrating mindfulness into regular positive reappraisal practice can promote well-being beyond practicing reappraisal alone. Moreover, this study probed for more study on emotion regulation 
interventions with the integration of positive appraisal and mindfulness techniques.

As Zentangle ${ }^{\circledR}$ is a very new mindful art intervention, only a few studies were found related to it. In the research by Sufrin (2016), participants were given 20 minutes to draw Zentangle ${ }^{\circledR}$ after being explained the concept and process of creating a Zentangle ${ }^{\circledR}$. The intervention was a onetime process and participants' levels of stress, burden and anxiety were measure via short surveys right after the intervention. Sufrin (2016) adopted quasi-experimental design without a control group which involved self-report measures. It was the first quasiexperimental study to suggest Zentangle ${ }^{\circledR}$ as a means of art therapy. The results of this study show that Zentangle ${ }^{\circledR}$ intervention would significantly decrease stress and anxiety.

Yu (2017) also applied only one group intervention, but the duration on intervention was much longer. Participants were required to attend a 4 weeks workshop. The workshop took place once per week, 3 hours per time, thus the duration of the workshop was 12 hours in total. Other than creating Zentangle ${ }^{\circledR}$, meditation and group sharing sessions were involved in the workshop. Although there was no significant result found on the effect of Zentangle ${ }^{\circledR}$ for stress, the study shows that there were positive emotional changes and the gap between high and low scales of pressure was reduced. The positive emotion mentioned here was measured by means of interview questions, in which respondents describe their feelings as enjoyable. Although the positive emotion was not measured specifically on positive affect (PA), it was nonetheless very close to the definition and characteristics of PA employed in the current study.

On the other hand, in the research by Pu (2017), instead of creating Zentangle ${ }^{\circledR}$, the participants of this research were required to admire Zentangle ${ }^{\circledR}$ drawings integrated with fish script for 20 minutes. Unlike the two journals studied before, this research has treatment and control group. While treatment group admired Zentangle ${ }^{\circledR}$ with fish script for 20 minutes, the control group from this study rested for 20 minutes. Research by $\mathrm{Pu}$ (2017) is a quantitative research where HRV analysis equipment was adopted to monitor participants' heart rate variability, stress level and TP index value. There was a significant result that admiring Zentangle ${ }^{\circledR}$ with fish script is a better way to relieve stress than merely resting for 20 minutes.

\section{Statement of Problem}

4 out of 10 Malaysians suffered from mental health problems (The Star Online, 2017). Ministry of Health Malaysia reported that 9,000 000 people in Malaysia are having psychological distress, and $6.3 \%$ of Malaysians are thinking about death and suicide. Suicide is another rising issue in Malaysia, especially among Malaysian youths. Averagely 227 Malaysian committed suicide per year, from year 2010 to September 2016.

With arising concern on the mental health of Malaysian youth, many studies have been done examining well-being of university students. Most of the studies focused on the pathological aspects i.e. stress, anxiety and depression (See \& Chuah, 2015; Salam, Yousuf, Bakar \& Haque, 2013; Rahman \& Noor, 2014). Absence of pathological mental issues does not indicate good mental health. Therefore, this study investigates whether mindful art therapy could improve subjective well-being of university students by regulating positive affect or emotions instead of focusing on the pathological aspects. Past studies related to mental health focused expansively on pure science students. However, mental health issues exist widely among the youth population regardless of their academic disciplines and therefore, studies beyond the pool 
of pure science students is warranted.

Overall, research specifically on the potential impact of Zentangle ${ }^{\circledR}$ as a mindful art therapy is in its infancy. Only one study on it was found in the context of the United States, while only several others were conducted in Taiwan. However, to our best knowledge, no empirical studies have been conducted within the Malaysian context. Among the studies found, no previous studies directly assessed the impact of Zentangle ${ }^{\circledR}$ as a mindful art therapy on positive affect (PA). The current study is the first, or one of the first to implement Zentangle ${ }^{\circledR}$ specifically intended to promote the subjective well-being of first year teacher trainee students at undergraduate level in a Malaysian public university, regarding PA.

\section{Research Objectives}

The overarching goal of this study is to investigate the impact of mindful art-therapy on positive affect among undergraduate students in a Malaysian public university.

Specifically, this research seeks to answer the following questions:

i. What is the level of positive affect among undergraduate students in a Malaysian public university prior to receiving mindful art therapy?

ii. What is the stress level of undergraduate students in a Malaysian public university prior to receiving mindful art therapy?

iii. What is the relationship between stress levels with level of positive affect among undergraduate students in a Malaysian public university prior to receiving mindful art therapy?

iv. What is the impact of mindful art therapy on improving positive affect among undergraduate students in a Malaysian public university?

\section{Research Hypotheses}

The following hypotheses were postulated corresponding to the research objective:

i. There is a significant correlation between stress level and the level of positive affect among undergraduate students in a Malaysian public university prior to receiving mindful art therapy.

ii. There is a significant difference in the level of positive affect after the participants experienced mindful art therapy designed to induce positive emotion.

\section{Research Methods}

Research Design

Fundamentally, this study is a quantitative, single group pretest-posttest design with aims to evaluate the effectiveness of using mindful art therapy to regulate positive emotions of undergraduate students pursuing their bachelor's degree in a Malaysian public university. In this study, the focus is on increasing positive affect of the participants. The independent variable in this study is the Zentangle ${ }^{\circledR}$ intervention. 
Vol. 8, No. 4, 2019, E-ISSN: 2226-6348 @ 2019 HRMARS

\section{Location of Study}

Previous studies (Teh et al., 2015; See \& Chuah, 2015) demonstrated that Malaysian undergraduate students have high rates of emotional disturbances, indicating low levels of psychological well-being. The current study selected one of the public research universities in Malaysia as study location. It should be declared that location threats might exist as the study was conducted in a classroom. Participants' emotions might be affected as the study was conducted in the classroom where they have their usual class, with the presence of their lecturer.

\section{Population and Sampling}

In this research, the target population were first year undergraduate students pursuing their bachelor's degree in a Malaysian public university. The sampling process involves selecting individuals whom are representative of the population in which they were selected from. After careful considerations on the aspects of budget, feasibility, and representativity, our current study adopted cluster sampling method to select samples to participate in this study. Instead of individuals, cluster sampling method adopted groups as the sampling unit while obtaining samples. In this study, a cluster of first year teacher trainee students at undergraduate level were selected from several clusters of students from the same Malaysian public university. As the minimum number of subjects required for experimental or quasi-experimental research is 30 people (Fraenkel, Wallen, \& Hyun, 2016), the selected cluster fulfils this requirement by having 48 students in the group.

\section{Instrumentation}

The investigation tool adopted for this study is the Positive and Negative Affect Schedule (PANAS) invented by Watson, Clark and Tellegen (1988). This instrument is used widely and globally. It has enough psychometric properties in measuring emotional affect (Watson, Clark \& Tellegen, 1988; Watson \& Walker, 1996). PANAS is a self-report measurement consisting 20 items. Among the 20 items, 10 items describe pleasant emotions and feelings, measuring the domain of positive affect (PA), while the other 10 items depict unpleasant emotions and feelings, measuring the domain of negative affect (NA). Since the PA and negative affect of PANAS are claimed to be independent measures (Crawford \& Henry, 2004), and since this study aims to focus on promoting positive emotions of participants, only the 10 items measuring positive affect (PA) were adopted for the purpose of the current report.

All items of PANAS were rated in five Likert-type points, ranging from "very slightly or not at all" to "extremely". Participants were asked to choose only one answer for each item to indicate the extent of their feelings at that present moment. Based on the scoring instruction, the rate for PA are to be converted into scores ranging from 1 to 5 , and to be added together to obtain the total scores. The range of the total scores is from 10 to 50 . Higher scores represent higher levels of PA, indicating "high energy, full concentration, and pleasurable engagement", while low scores suggest "sadness and lethargy" (Watson, Clark \& Tellegen, 1988).

Another instrument utilized in this study is the perceived stress scale invented by Cohen, Kamarck and Mermelstein (1983) to measure the degree which one perceives the situations of his/her life as stressful. This scale has 14 items, assessing stressful events in past month. For example, participants will be asked to rate how often they have felt nervous or "stressed" in the 
past month. The items are measured in five-points Likert scale, ranging from "never", "almost never", "sometimes", "fairly often" to "very often. Total score ranging from 0 to 56 . The greater the total score, indicates the higher the perceived stress and vice versa.

\section{Validity and Reliability}

PANAS has been widely used by many researchers to assess individual's positive affect (PA) and negative affect worldwide. To meet the needs of tremendous usage in studies conducted in Malaysia, PANAS had also been translated to the Malay language (Osman \& Jaffer, 2012; Yap, 2015), indicating that PANAS is applicable in the Malaysian context.

PANAS has a high factorial validity score of .95 for its positive affect scale (Watson, Clark \& Tellegen, 1988). The same instrument will be applied for both the pre-test and the post-test. To ensure internal validity and to minimize repeated testing threat, items in the post-test questionnaire are rearranged in sequence differing from the sequences in the pre-test questionnaire.

Reliability is another important consideration to ensure consistent results from instrumentation. PANAS positive affect scale is reported to be highly reliable (in terms of internal consistencies of items), with Cronbach's $\alpha .89$ (Watson, Clark \& Tellegen, 1988). It exhibits high stability in its reliability score in different researches over time. For instance, it scored alpha coefficients of .89 (Crawford \& Henry, 2004), .83 (Mustapha, 2015) and .81 (Yap, 2015) in different context. In other words, the PANAS positive affect scale is valid and reliable to be used as the instrument to measure the level of positive affect in this study. In addition, the Cronbach's $\alpha$ score for this study is .90 , which indicates reasonably high reliability.

On the other hand, the second instrument applied in this research - the perceived stress scale - also reported to have excellent psychometric features and have high validity (Eskin, Harlak, Demirkiran, \& Dereboy, 2013). It has scores of .85 and .85 for its test-retest reliability. It was widely used and had been translated to many versions including the Malay version (Sandhu, Ismail \& Rampal, 2015). The perceived stress scale has been applied in the Malaysian context to assess stress level of university students (Shoib, 2015; Al-Shagga et al., 2015).

\section{Data Collection}

Ethics approval was obtained before conducting the study. After granted permission, we approached an experienced Certified Zentangle ${ }^{\circledR}$ teacher (CZT) to seek permission for her willingness to conduct the Zentangle ${ }^{\circledR}$ intervention. The purpose of study was explained, and consent was gained to ensure Certified Zentangle ${ }^{\circledR}$ teacher participated in the study voluntarily.

At the same time, we started to select samples from the accessible population. Then, permission from the lecturer of the selected cluster of students was obtained to conduct the study. Next, we coordinated between the lecturer and the Certified Zentangle ${ }^{\circledR}$ teacher for their availability so that the time and date to conduct the experiment could be determined. When the time and date were confirmed, appointment to conduct the study was made with the lecturer, together with her students, as well as with the Certified Zentangle ${ }^{\circledR}$ teacher.

Several days before the experiment day, we briefed the Certified Zentangle ${ }^{\circledR}$ teacher (CZT) and the lecturer involved on the process of the whole experiment. On the day before the experiment day, we checked out the classroom of the study conducted and made sure all the 
facilities including air-conditioner, lights, speaker etc. are functioning well to ensure external validity by minimizing potential situation threats.

The experiment took place during regular class hours for students at undergraduate level, in the selected Malaysian public university. It started with the distribution of the questionnaire. The questionnaire consisted of 4 parts: purpose of the study, consent letter, demographic data, Perceived Stress Scale and PANAS positive affect scale. After distributing the questionnaires and making sure every student gets the questionnaire, students were briefed on the purpose of the study. Consent was obtained from students to ensure that they voluntarily participate in the study. Anonymity, confidentiality of personal information, and the right to withdraw from the study were assured before students started filling in the questionnaire.

Respondents were recommended not to put their names on the questionnaire to ensure confidentiality. Explanation on the use of the questionnaire as well as its contents was given, and students were advised to pick only one answer for each item. The participants completed the questionnaires in approximately 30 minutes. In between, we were ready to help and approach any participants who raised their hands up for inquiries. Data were collected once the participants completed the questionnaires in the classroom.

While students were filling in the questionnaire, we distributed a black ink pen, a pencil and two square tiles to each participant for use later. When we were done collecting all the questionnaires, the CZT was introduced. Then we passed the session to CZT who then conducted the Zentangle ${ }^{\circledR}$ intervention session.

After the Zentangle ${ }^{\circledR}$ intervention, we distributed post-test questionnaire consisting only the PANAS positive affect scale to all students. Students were briefed on the content and the use of the questionnaire before they started filling the form. After approximately 15 minutes when all participants completed the questionnaire, data were collected in the classroom.

The whole data collection process including pre-test, intervention and post-test took about 3 hours. For both pre-test and post-test sections, the confidentiality was secured by coding the questionnaires. Once the survey was done, all data collected were kept in a cabinet. Only the first researcher has access to it.

\section{Data Analysis}

We first conducted data preparation tasks including data screening, data cleaning and screening of normality. Questionnaire sets with missing values exceeding $10 \%$ were eliminated from the data analysis. Of the total of 48 sets of questionnaires collected, 3 sets of questionnaires were excluded on the cause of major incompleteness. On this account, 45 participants were preserved for further analysis.

Tests for normality were conducted using IBM SPSS version 22 to determine the choice of test to be conducted. As computed, the data of current study is normally distributed as the data stayed closely to a linear line. On that account, parametric test was chosen to be applied to analyse the data of current study.

\section{Findings}

A total of 48 undergraduate students from a public Malaysian university participated in this study. However, due to missing data, only 44 undergraduates were pertained for the study. 
Respondents were young adults aged between with mean age for 44 respondents was 21.05 years (SD $=1.033$. Female respondents $(n=35,79.5 \%)$ who participated in this study was more than twice the number of male respondents $(n=9,20.5 \%)$. Out of 44 respondents, majority of them were Malays $(n=30,68.2 \%)$, followed by Chinese $(n=8,18.2 \%)$, other ethnics $(n=5,11.4 \%)$ and Indian ( $n=1,2.3 \%$ ). This somehow suggested the representativeness of the Malaysian context. In terms of nationality, there were $88.6 \%(n=39)$ Malaysians, $9.1 \%(n=4)$ Chinese originally from People's Republic of China, and 2.3\% $(n=1)$ Iranian who took part in the study. Most of the respondents showed interest in art. Out of 44 students, $86 \%$ ( $n=38$ ) of them reported that they are interested in art, and only $13.6 \%(n=6)$ of them showed no interest in art. Regarding meditation experience, majority of them (79.5\%) do not have experience in this. Only $18.2 \%(n=8)$ practiced meditation such as yoga. Out of the 8 of them who meditated, only 2 of them are frequently practicing it.

More than half students (55\%) belong to first generation university student, which means neither of their parents graduated from a four-year college or university. Almost all the participants $(97.7 \%)$ were enrolled for 12 or more credit hours for the current semester. Among the 44 undergraduate students, a majority of $95.5 \%$ of them were not on academic probation. This indicates that in average, participants of this study were performing well in their academics.

Regarding self-report on satisfaction of current life, it was found that majority of the respondents were somewhat satisfied (38.6\%) and reacted neutrally (29.5\%) to their current life satisfaction. $15.9 \%$ of them were very satisfied with their current living situation; the other $15.9 \%$ stated that they were very dissatisfied with their current life. Financially, more than half of them (56.86\%) had their government loans funding for their education. $22.72 \%$ of them were paying for their own school fees, while $15.92 \%$ paid some of their education fees on their own and the rest were covered by their parents or guardians. Only $4.50 \%$ of the students received full scholarship sponsoring their educational costs.

\section{Level of Positive Affect Prior to Receiving Mindful Art Therapy}

In this section, we examine the level of subjective well-being of samples in terms of positive affect (PA) before they underwent experiencing the mindful art therapy. Table 1 shows the mean score for the PA scale before the intervention was 29.84 (SD = 7.471). The score ranges from 13 to 49 .

Table 1 PA level of respondents

\begin{tabular}{l|c}
\hline & Positive Affect (Pre-test) \\
\hline Mean Value & 29.84 \\
Standard Deviation & 7.471 \\
Minimum & 13 \\
Maximum & 49 \\
\hline
\end{tabular}

The PA score was divided into three categories: low, moderate and high. Students with PA score 22.369 and below is categorized under the low PA level group; Students whose score between 22.370 to 37.311 are categorized into the "moderate" group; while students who scored 37.312 and above are indicated to have high level of PA. Figure 4.8 shows the distribution of 
respondents in the three categories of PA level. It is obvious that majority of the respondents $(n=28,59.6 \%)$ are having moderate level of PA, while 9 respondents (19.1\%) reported high level of PA and 7 respondents (14.9\%) have low levels of PA.

Independent two-tailed t-test was used to compare the means of two different groups (Andy Field, 2005). Current research applies independent t-test to study the extent to which the variable in the research is related to various variables. In terms of gender, participants' level of positive affect (PA) indicates that there is no significant difference in the mean level of PA for male respondents $(M=30.78, S D=6.016)$ and female respondents $[M=29.60, S D=7.860 ; t(42)$ $=0.42, p=.68$.

The mean scores of participants' level of positive affect (PA) based on their interest in art was also tabulated. Results showed that there were no significant difference in the mean levels of PA for respondents who were interested in art $(M=34.21, S D=9.422)$ and respondents who did not show interest in art $[M=32.17, S D=13.761 ; t(42)=0.46, p=.65]$.

In regards to their scores on PA based on whether or they have had experience with meditation, results showed that there were no significant difference in the mean level of PA for respondents who had experienced meditation $(M=35.75, S D=8.328$ ) over those who never experienced meditation $[\mathrm{M}=33.53, \mathrm{SD}=10.330 ; \mathrm{t}(42)=0.57, \mathrm{p}=.57]$.

Independent two-tailed t-test was computed to demonstrate the mean scores of participants' level of positive affect (PA) based credit hours of which the participants enrolled in the current semester. Results showed that the mean level of PA for respondents who enrolled 12 or more credit hours during the current semester the study was conducted $(M=29.40, S D=$ 6.942) had significantly greater level of positive affect prior to intervention when compared to the respondents who enrolled 6 to 11.5 credit hours during that particular semester $[M=33.53$; $\mathrm{t}(42)=2.79, \mathrm{p}=.008]$.

Independent two-tailed t-test did not indicate a statistically significant difference between the mean scores of participants' level of positive affect (PA) between the undergraduate students who belong to first generation university students $(M=30.63, S D=7.494)$ and those who were not a first generation university student $[\mathrm{M}=28.90, \mathrm{SD}=7.525 ; \mathrm{t}(42)=0.76, \mathrm{p}=.45]$.

Independent two-tailed t-test do not suggest a statistically reliable difference between the mean scores of participants' level of subjective well-being in term of positive affect (PA) between the undergraduate students who were on academic probation $(M=39.00, S D=2.828$ ) and those who were not on academic probation $[M=29.40, S D=7.352 ; t(42)=1.82, p=.08]$.

\section{Level of Stress Prior to Receiving Mindful Art Therapy}

This section explores on the stress level of participants prior to receiving the mindful art therapy, Zentangle ${ }^{\circledR}$. Table 4.9 shows the descriptive statistic on the result. The mean score of respondents for stress level is 29.30 (SD = 6.271) as shown in Table 2. The minimum score is 15 and maximum is 48 .

The level of stress was divided into three categories: low, moderate and high. From figure 4.9 , out of 44 participants, $22(46.8 \%)$ of them were in the moderate category of stress level, following by high stress level category $(n=16,34 \%)$, while the category consisted of least number of respondents was low stress level group ( $n=6,12.8 \%$ ). 
Vol. 8, No. 4, 2019, E-ISSN: 2226-6348 @ 2019 HRMARS

Table 2 Stress level of respondents

\begin{tabular}{l|c}
\hline & Stress Level (Pre-test) \\
\hline Mean Value & 29.30 \\
Standard Deviation & 6.271 \\
Minimum & 15 \\
Maximum & 48 \\
\hline
\end{tabular}

\section{Associations between Stress Level and Positive Affect Prior to Receiving Mindful Art Therapy}

Pearson's correlation was computed to examine the relationship between level of stress and level of positive affect (PA) prior to experiencing mindful art therapy Zentangle ${ }^{\circledR}$ among the undergraduate students participated in this study. Result shows that no significant relationship was found between the two variables, $r(42)=-0.222, n=44, p=0.147>0.01$. Hence, the first hypothesis of the current study is rejected. The result of the statistical analysis on correlation is summarized with a scatter plot shown in Figure 1.

Fig. 1 Correlation between pre-test PA score and pre-test score for stress level

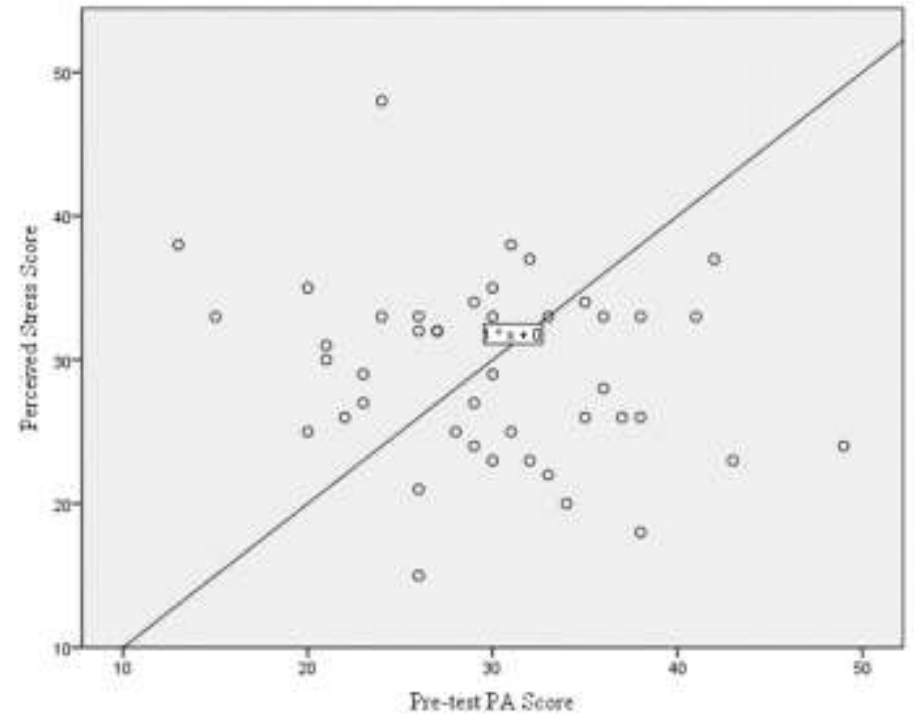

Impact of Mindful Art Therapy on Respondents' Positive Affect

This section reports on statistical analyses of respondents' positive affect regulation condition, particularly the level of positive affect (PA) of subjective well-being before and after experiencing the mindful art therapy. Mean score for PA increases from 29.84 (SD = 7.471) before the intervention to 33.93 (9.945) after the intervention. Figure 2 gives a clearer view on the rise of the mean score for the PA before and after participants received the mindful art therapy. 
Vol. 8, No. 4, 2019, E-ISSN: 2226-6348 @ 2019 HRMARS

Fig. 2 Changes on the mean for PA score before and after intervention

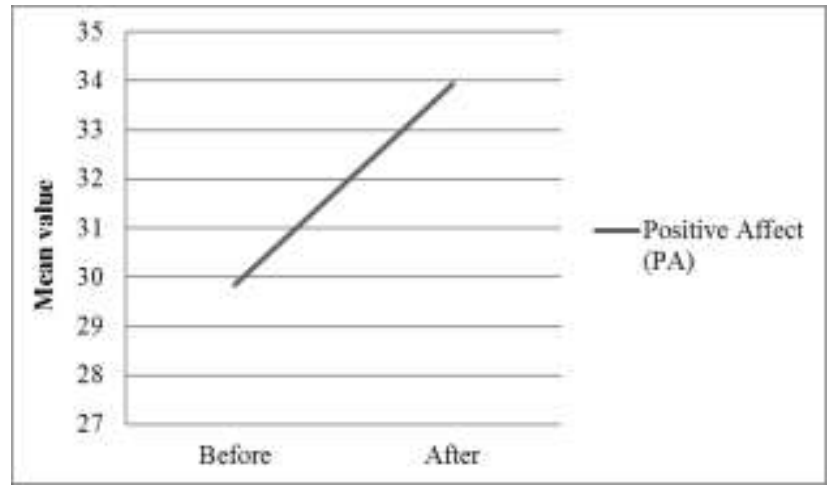

Pearson's correlation was computed to identify if there is a relationship between level of PA before and the PA level after intervention. Results show that the levels of PA for pre-test and post-test are significantly correlated, $r(44)=0.482, n=44, p=0.001$, two-tailed. A scatter plot summarizes the results (Figure 3 ). Overall, there was a strong positive correlation between PA score prior to mindful art therapy intervention and PA score after the same intervention. Higher PA score for pre-test was correlated with higher PA score for post-test.

Fig. 3 Correlation between pre-test score and post-test score for positive affect

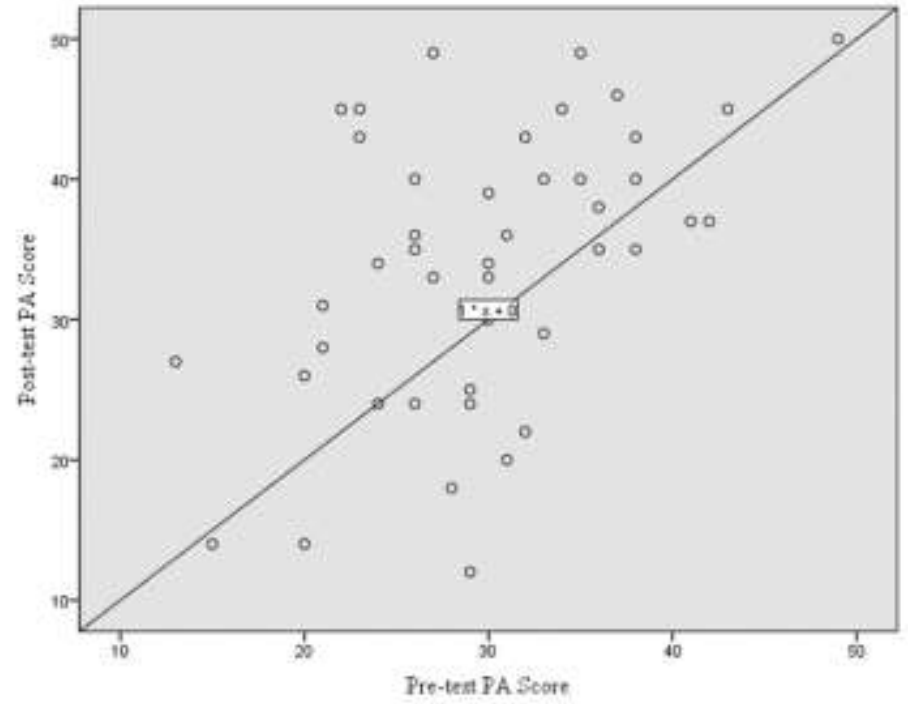

To obtain more statistical information, a paired t-test was tabulated on 44 participants of this research, whom are pursuing their study at undergraduate level, to explore if there was a significant mean difference in the PA score before and after students experienced Zentangle ${ }^{\circledR}$. We found that after students experienced the intervention, there was a statistically significant increase of $4.091(95 \% \mathrm{Cl},-6.863$ to -1.319$)$ PA score, $t(43)=-2.976, p=<0.005$. As $p=0.005>$ 0.05 , it shows that there is significant difference of scores before and after the intervention.

A histogram was plotted to compare the level of positive affect (PA) in categories, among respondents. The levels of positive affect before and after the intervention are compared in categories too. As seen in Figure 4, the number of respondents who initially had low levels of PA $(n=7,14.9 \%)$ decreased to $6(12.8 \%)$ persons after the Zentangle ${ }^{\circledR}$ intervention. In addition, 
number of respondents in the "moderate" category dropped from 28 (59.6\%) person to 22 $(46.8 \%)$ person too. While the number of respondents $(n=16,34 \%)$ at the high PA level category after experiencing Zentangle ${ }^{\circledR}$ almost doubled the number of people in the same category before intervention $(n=9,19.1 \%)$.

Fig. 4 Level of PA among respondents before and after intervention

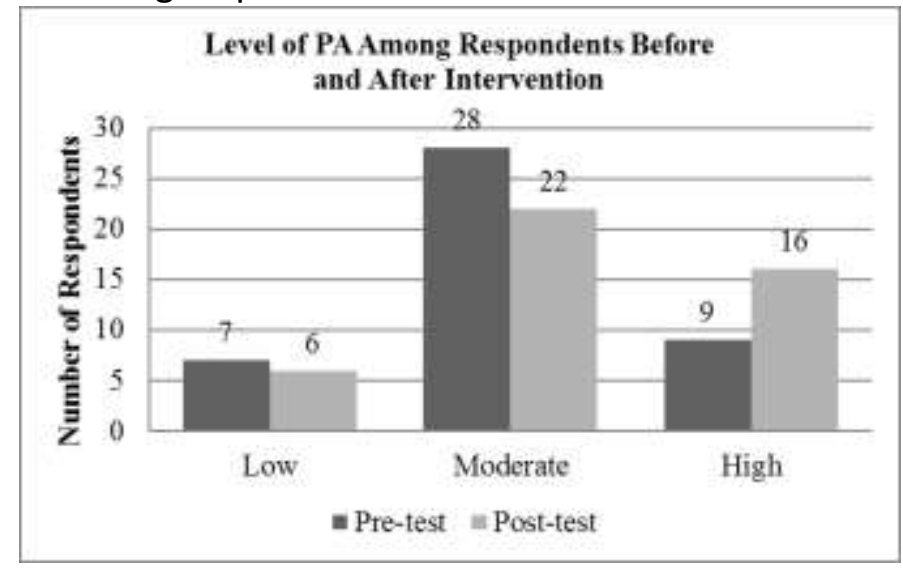

\section{Discussion}

\section{Level of Positive Affect Prior to Receiving Mindful Art Therapy}

This study found that the mean level of positive affect among the participants was at the moderate level. As positive affect indicates subjective well-being, and subjective well-being is associated with mental health (Aziz, 2016), it can be inferred that most undergraduate students who participated in this study were neither very healthy nor unhealthy in their state of mental health.

Inferential information was obtained using independent t-tests. Results revealed that there were no significant differences in participants' mean level of subjective well-being in terms of positive affect based on gender, interest in art, experience in meditation, first generation university student status and academic probation status. These findings suggested that these variables do not affect the level of positive affect.

\section{Level of Stress Prior to Receiving Mindful Art Therapy}

The level of stress of first year teacher trainee students at undergraduate level in a Malaysian public university was investigated and we found that although most participants $(46.8 \%)$ of this study were having moderate level of stress, many of them (34\%) are having high stress levels as well. There were only $12.8 \%$ difference in the number of respondents between moderate stress level category and high stress level category.

It is pertinent to note that this study was conducted at the beginning of a new semester, when students were not yet engaged with heavy workloads and have not yet encountered stress regarding exams. Even without the presence of these events, majority of the participants in this study were having either moderate or high levels of stress. This indirectly indicates that our hypothesis that stress at university level is not specific to students in the hard sciences, but rather, any student can be affected by high levels of stress regardless of their academic 
disciplines. In fact, the general population of this age group might also be facing high stress levels. As mental health is defined as a state of being completely well with the absence of pathological elements (Keyes, 2005), it can be suggested that given the findings on their overall stress levels, our study participants' state of mental health needs further improvement.

Independent two-tailed t-test was once again computed to study to which extent the variable in the current study relates to other variables. Our study showed that there were no significant differences found in respondents' mean level of stress based on gender, credit hours enrolled in current semester, whether participants belong to first generation university student, and academic probation status of participants. The finding based on gender of current study contradicts with other researches which demonstrated gender differences in relation to stress (Lee \& Cho, 2016; Jiang, Chang \& Sullivan, 2014; Bonneville-Roussy et al., 2017). The other three variables: credit hours enrolled in current semester, whether students belong to first generation university student, and whether the participants are on academic probation, can be categorized under academic factors. Academic factors had been historically found to have contributed to stress, hence the emergence of the term "academic stress" which to a certain extent, has been normalized in most cultures due to its commonality. However, in contrast with numerous studies related to academic factors and stress (e.g. Blashill, 2016), our study found no significant relationship between stress level and the academic variables mentioned.

\section{Relationship between Stress Level and Positive Affect Prior to Receiving Mindful Art Therapy}

This study applied Pearson's correlation to examine the relationship between stress level and positive affect before respondents experience the mindful art therapy. Results showed that there was no significant relationship found between the variables. This was in contrast with previous studies stating that positive affect is indirectly correlated with stress (Fredrickson, 2001; Corral-Frias, Nadel, Fellous \& Jacobs, 2016). However, in both previous studies mentioned, positive affect served as a mediator to stress coping and resilience. It was not concluded that there was a direct relationship between both variables.

On the other hand, our finding on insignificant relationship between stress and positive affect was supported by studies conducted by Civitci (2015), Jung and colleagues (2016) and Wang, Xie and Cui (2016). Although the relationship between stress level and the level of positive affect prior to receiving mindful art therapy was not statistically significant, there was a medium effect size $(r=-.22)$ and it was in the direction of our hypothesis, thus we theorize that the result might be due to the sample size. There could plausibly be a significant relationship given greater sample size.

\section{Impact of Mindful Art Therapy on Respondents' Positive Affect}

This study found that participants' level of positive affect significantly increased after experiencing the mindful art therapy, Zentangle ${ }^{\circledR}$. Pearson's correlation was conducted and found that the level of positive affect among undergraduate students in a Malaysian public university prior to Zentangle ${ }^{\circledR}$ intervention positively correlated to the level of positive affect after participants experienced mindful art therapy Zentangle ${ }^{\circledR}$. We noticed that participants whose level of positive score was already high before the intervention also tended to increase even higher after the intervention. 
Vol. 8, No. 4, 2019, E-ISSN: 2226-6348 @ 2019 HRMARS

The difference between the level of positive affect before and after Zentangle ${ }^{\circledR}$ intervention was examined using paired sample t-test. It was found that there was a significant difference of mean in level of positive affect among the participants before and after experiencing mindful art therapy Zentangle ${ }^{\circledR}$. Based on Figure 4, it could be visually seen that there was a great increase in number of participants who were at the category having high levels of positive affect. This shows that the mindful art therapy, Zentangle ${ }^{\circledR}$ could significantly increase the positive affect of those who practiced it. This finding is in line with previous studies (e.g., Kaimal \& Ray, 2017; Kim, Kim, Choe \& Kim, 2018). As positive affect is one of the main components of subjective well-being according to the tripartite model (Clark \& Watson, 1991), we can conclude that Zentangle ${ }^{\circledR}$ could potentially improve the subjective well-being of people who practice it. This suggestion is parallel to studies done by Pogrebstova and colleagues (2017), Han, Gibson, Eggett and Parker (2017) and Mustapha (2015).

\section{Conclusion}

This study aligns with the increasingly popular positive psychology, encouraging the study on subjective well-being among university students to be extended to overall population instead of merely focusing on science students. Fundamentally, the present study investigated the impact of mindful art therapy, Zentangle ${ }^{\circledR}$ on positive affect among first year teacher trainee students at undergraduate level in a Malaysian public university. We first examined the level of positive affect among the participants before they experience mindful art therapy Zentangle ${ }^{\circledR}$ and found that majority of them had moderate level of positive affect. Despite the positive affect, our findings show that the stress level of the participants were moderately high, with $46.8 \%$ of them at the average level of stress and $34 \%$ of them having high levels of stress.

Although stress seems to be always connected to well-being, this study found no significant relationship between level of stress and level of positive affect prior to the mindful art therapy intervention. Supported by several other previous studies (Civitci ,2015; Jung et al., 2016; Wang, Xie \& Cui, 2016), our current research suggest that high levels of positive affect do not predict lower levels of stress although high levels of positive affect indicates high levels of subjective well-being (Cohen \& Pressman, 2006; Fredrickson, 2001; Clark \& Watson, 1991).

Our present study also compared the mean level of positive affect in participants before and after they experience Zentangle ${ }^{\circledR}$. Results showed that participants' mean level of positive affect significantly increased after they receive mindful art therapy Zentangle ${ }^{\circledR}$. Besides, descriptive statistics showed that the number of participants with high levels of positive affect increased from $19.1 \%$ to $34 \%$ and number of people with low levels of positive affect dropped from $14.9 \%$ to $12.8 \%$ after participants experienced mindful art therapy. This suggest that Zentangle ${ }^{\circledR}$, like many other mindful art therapies such as Mandala, is potentially effective in increasing positive affect levels, thereby improving subjective well-being.

The current study is an important step forward in mindful art therapy and subjective wellbeing research. It introduces a relatively new mindful art therapy, Zentangle ${ }^{\circledR}$ in to the Malaysian context. Within the limitations of the study, we conclude that the mindful art therapy is possibly effective in increasing the levels of positive affect among undergraduate students in a Malaysian public university, which is pertinent in terms of reducing suicidal ideation (Rajappa et al., 2012; Lim, Cheong \& Saw, 2015). Besides, the present study highlighted that overall, undergraduate 
INTERNATIONAL JOURNAL OF ACADEMIC RESEARCH IN PROGRESSIVE EDUCATION AND DEVELOPMENT

Vol. 8, No. 4, 2019, E-ISSN: 2226-6348 @ 2019 HRMARS

students might be struggling with generally the same mental health issues, probing the need to increase well-being of the youth.

\section{Corresponding Author}

Aini Marina Ma'rof (PhD), Faculty of Educational Studies, Universiti Putra Malaysia, 43400 UPM Serdang, Malaysia.

Email: ainimarina@upm.edu.my

\section{References}

Al-Shagga, M. A., Nasir, M. N. Z., Behzadnia, A. Jasamai, M., Al-Absi, A. M. \& Al-Dubai, S. A. R. (2015). Perceived stress and sources of stress among pharmacy students in Malaysian public and private universities: A comparative study. Pharmacy Education, 15(1), 64-68.

Andrews, F., \& Withey, S. (1976). Social indicators of well being (1st ed., pp. 63-104). New York: Plenum Press.

ASEAN. (2016). ASEAN Mental Health Systems Report (pp. 41 \& 90). Jakarta. Retrieved from http://asean.org/storage/2017/02/55.-December-2016-ASEAN-Mental-HealthSystem.pdf

Ashby, F., Isen, A., \& Turken, A. (1999). A neuropsychological theory of positive affect and its influence on cognition. Psychological Review, 106(3), 529-550.

Aziz, A. (2016). Exploration of Well-Being through Art Media Preference and Emotion Regulation Strategies (Master of Arts). Notre Dame de Namur University.

Blashill, M. M. (2016). Academic stress and working memory in elementary school student (Ph. D). University of Northern Colorado.

Bonneville-Roussy, A., Evans, P., Verner-Filion, J., Vallerand, R., \& Bouffard, T. (2017). Motivation and coping with the stress of assessment: Gender differences in outcomes for university students. Contemporary Educational Psychology, 48, 28-42.

Carl, J., Soskin, D., Kerns, C., \& Barlow, D. (2013). Positive emotion regulation in emotional disorders: A theoretical review. Clinical Psychology Review, 33(3), 343-360.

Chong, S. A., Abdin, E., Vaingankar, J. A., Heng, D., Sherbourne, C., Yap, M., ... \& Subramaniam, M. (2017). A population-based survey of mental disorders in Singapore.

Çivitci, A. (2015). The moderating role of positive and negative affect on the relationship between perceived social support and stress in college students. Educational Sciences: Theory and Practice, 15(3), 565-573.

Clark, L. A., \& Watson, D. (1991). Tripartite model of anxiety and depression: psychometric evidence and taxonomic implications. Journal of abnormal psychology, 100(3), 316.

Clark, L. A., Watson, D., \& Leeka, J. (1989). Diurnal variation in the positive affects. Motivation and Emotion, 13(3), 205-234.

Cohen, S., \& Pressman, S. D. (2006). Positive affect and health. Current Directions in Psychological Science, 15(3), 122-125.

Cohen, S., Kamarck, T., \& Mermelstein, R. (1983). A global measure of perceived stress. Journal of health and social behavior, 385-396.

Cohn, M. A., Fredrickson, B. L., Brown, S. L., Mikels, J. A., \& Conway, A. M. (2009). Happiness unpacked: positive emotions increase life satisfaction by building 
DEVELOPMENT

Vol. 8, No. 4, 2019, E-ISSN: 2226-6348 @ 2019 HRMARS

resilience. Emotion, 9(3), 361.

Corral-Frías, N. S., Nadel, L., Fellous, J. M., \& Jacobs, W. J. (2016). Behavioral and self-reported sensitivity to reward are linked to stress-related differences in positive affect. Psychoneuroendocrinology, 66, 205-213.

Crawford, J. R., \& Henry, J. D. (2004). The Positive and Negative Affect Schedule (PANAS): Construct validity, measurement properties and normative data in a large non-clinical sample. British journal of clinical psychology, 43(3), 245-265.

Fredrickson, B. L., \& Joiner, T. (2002). Positive emotions trigger upward spirals toward emotional well-being. Psychological science, 13(2), 172-175.

Diener, E. (2000). Subjective well-being: The science of happiness and a proposal for a national index. American Psychologist, 55(1), 34-43.

Drake, J., Coleman, K., \& Winner, E. (2011). Short-term mood repair through art: effects of medium and strategy. Art Therapy, 28(1), 26-30.

Foster, M. (1992). Experiencing a "creative high". The Journal of Creative Behavior, 26(1), 29-39.

Fraenkel, J., Wallen, N., \& Hyun, H. (2016). How to design and evaluate research in education, ninth edition (9th ed.). New York: McGraw-Hill Higher Education.

Han, X., Gibson, J., Eggett, D., \& Parker, T. (2017). Bergamot (Citrus bergamia) essential oil inhalation improves positive feelings in the waiting room of a mental health treatment center: A pilot study. Phytotherapy Research, 31(5), 812-816.

Hoppmann, C., Gerstorf, D., Willis, S., \& Schaie, K. (2011). Spousal interrelations in happiness in the seattle longitudinal study: Considerable similarities in levels and change over time. Developmental Psychology, 47(1), 1-8.

Jang, S., Kang, S., Lee, H., \& Lee, S. (2016). Beneficial effect of mindfulness-based art therapy in patients with breast cancer-A randomized controlled trial. EXPLORE: The Journal Of Science And Healing, 12(5), 333-340.

Jiang, B., Chang, C., \& Sullivan, W. (2014). A dose of nature: Tree cover, stress reduction, and gender differences. Landscape and Urban Planning, 132, 26-36.

Kaimal, G., \& Ray, K. (2017). Free art-making in an art therapy open studio: changes in affect and self-efficacy. Arts \& Health, 9(2), 154-166.

Kesebir, P., \& Diener, E. (2008). In defense of happiness.

Keyes, C. (2005). Mental illness and/or mental health? Investigating axioms of the complete state model of health. Journal of Consulting and Clinical Psychology, 73(3), 539-548.

Kim, H., Kim, S., Choe, K., \& Kim, J. (2018). Effects of mandala art therapy on subjective wellbeing, resilience, and hope in psychiatric inpatients. Archives of Psychiatric Nursing, 32(2), 167-173.

Krahula, R. (2012). One zentangle a day. Beverly, Mass.: Quarry Books.

Lee, J., \& Cho, Y. (2016). Gender differences in job stress and stress coping strategies among Korean nurses. International Journal of Bio-Science and Bio-Technology, 8(3), 143-148.

Lim, Y., Cheong, H., \& Saw, S. (2015). The correlation of video games with positive affect and negative affect among Utar (Perak campus) undergraduate students (Undergraduate). Universiti Tunku Abdul Rahman.

Losinski, M., Hughey, J., \& Maag, J. (2016). Therapeutic art: Integrating the visual arts into programming for students with emotional and behavioral disorders. Beyond Behavior, 
INTERNATIONAL JOURNAL OF ACADEMIC RESEARCH IN PROGRESSIVE EDUCATION AND DEVELOPMENT

Vol. 8, No. 4, 2019, E-ISSN: 2226-6348 @ 2019 HRMARS

25(1), 27-34.

Lyubomirsky, S., King, L., \& Diener, E. (2005). The benefits of frequent positive affect: Does happiness lead to success?. Psychological Bulletin, 131(6), 803-855.

Malchiodi, C. (2014). Calm Down and Get Your Zentangle On. Retrieved from Psychology Today: http://www.psychologytoday.com/blog/arts-and-health/201403/calm-down-and-getyour-zentangle

McManus, S., Bebbington, P., Jenkins, R., \& Brugha, T. (2016). Mental health and wellbeing in England: Adult psychiatric morbidity survey 2014. Leeds: NHS Digital. Retrieved from http://webarchive.nationalarchives.gov.uk/20180328130852tf_/http://content.digital.n hs.uk/catalogue/PUB21748/apms-2014-full-rpt.pdf/

Meeks, S., Shah, S., \& Ramsey, S. (2009). The pleasant events schedule - Nursing home version: A useful tool for behavioral interventions in long-term care. Aging \& Mental Health, 13(3), 445-455.

Mental Illness. (n.d.). Retrieved May 8, 2018 from National Institute of Mental Health: https://www.nimh.nih.gov/health/statistics/mental-illness.shtml

Monti, D., Peterson, C., Kunkel, E., Hauck, W., Pequignot, E., Rhodes, L., \& Brainard, G. (2006). A randomized, controlled trial of mindfulness-based art therapy (MBAT) for women with cancer. Psycho-Oncology, 15(5), 363-373.

Mustapha, M. (2015). Subjective well-being among Malaysian students (Ph. D.). University of Plymouth.

New Straits Times. (2017). Suicide on the rise among Malaysian youth. Retrieved from https://www.nst.com.my/news/exclusive/2017/05/243354/suicide-rise-amongmalaysian-youth

Okely, J., Weiss, A., \& Gale, C. (2017). The interaction between stress and positive affect in predicting mortality. Journal of Psychosomatic Research, 100, 53-60.

Osman, R., \& Jaffer, U. (2012). Investigating the perceived emotional experience of bilinguals in the acquisition of first and second languages: KIRKHS students as a case study. International Journal of Social Science and Humanity, 2(6), 554-556.

Park, C. L. (2015). Integrating positive psychology into health-related quality of life research. Quality of Life Research, 24(7), 1645-1651.

Pendleton, P. (1999). Painting a path of well-being: Art therapy as a link to mental health treatment. Art Therapy, 16(1), 31-36.

Peterson, C. (2015). 'Walkabout: Looking In, Looking Out": A mindfulness-based art therapy program. Journal of the American Art Therapy Association, 32(2), 78-82.

Pogrebtsova, E., Craig, J., Chris, A., O'Shea, D., \& González-Morales, M. (2017). Exploring daily affective changes in university students with a mindful positive reappraisal intervention: A daily diary randomized controlled trial. Stress and Health, 34(1), 46-58.

Pressman, S., \& Cohen, S. (2005). Does positive affect influence health?. Psychological Bulletin, 131(6), 925-971.

$\mathrm{Pu}, \mathrm{H}$. (2017). The study of stress relief by using the application of Zentangle with fish script (Master's thesis). Retrieved from National digital library of theses and dissertations in Taiwan. http://hdl.handle.net/11296/qwuw49

Rahman, Z., \& Noor, N. (2014). Prevalence and determinants of stress among medical students 
INTERNATIONAL JOURNAL OF ACADEMIC RESEARCH IN PROGRESSIVE EDUCATION AND DEVELOPMENT

Vol. 8, No. 4, 2019, E-ISSN: 2226-6348 @ 2019 HRMARS

of Universiti Sains Islam Malaysia ( USIM ). 'ulūm Is/āmiyyah Journal, 14, 157-170.

Rajappa, K., Gallagher, M., \& Miranda, R. (2012). Emotion dysregulation and vulnerability to suicidal ideation and attempts. Cognitive Therapy and Research, 36, 833-839.

Salam, A., Yousuf, R., Bakar, S., \& Haque, M. (2013). Stress among medical students in Malaysia: A systematic review of literatures. International Medical Journal, 20(6), 649-655.

Sandhu, Ismail, \& Rampal, (2015). The Malay version of the perceived stress scale (PSS)-10 is a realiable and valid measure for stress among nurses in Malaysia. The Malaysian Journal of Medical Sciences, 22(6), 26-31.

See, C. M., \& Chuah, J. Y. (2015). Mental Health and Wellbeing of the Undergraduate Students in a Research University: A Malaysian Experience. Social Indicators Research, 122(2), 539551.

Seligman, M., \& Csikszentmihalyi, M. (2000). Positive psychology: An introduction. American Psychologist, 55, 5-14.

Shoib, N. (2015). Stress, coping and life satisfaction: A study among reserve officer training units (palapes) and police undergraduate voluntary corps (suksis) of Universiti Malaysia Sarawak (Bachelor of Science). Universiti Malaysia Sarawak.

Springham, N. (2012). Guest editorial. International Journal of Art Therapy, 17(3), 87-89.

Sufrin, L. (2016). Examining burden and the effects of Zentangle for stress and anxiety in caregivers of people with Parkinson's disease (Master's thesis). Retrieved from Proquest.

Teh, C. K., Ngo, C. W., Zulkifli, R. A., Vellasamy, R., and Suresh, K. (2015). Depression, anxiety and stress among undergraduate students: A cross sectional study. Open Journal of Epidemiology, 5, 260-268. http://dx.doi.org/10.4236/ojepi.2015.54030

The Brunswick News. (2014). Zentangle offers opportunity to find inner peace via art. Retrieved from https://thebrunswicknews.com/life/zentangle-offers-opportunity-to-find-innerpeace-via-art/article_d030a5c0-ed09-53fe-b71d-e26ff30f8b5b.html

The Star Online. (2017). Depression: 40\% of Malaysians will suffer from mental health issues in their lifetime. Retrieved from https://www.thestar.com.my/news/nation/2017/04/02/malaysians-will-suffer-frommental-health-issues-in-their-lifetime/

Walsh, S., Chang, C., Schmidt, L., \& Yoepp, J. (2005). Lowering stress while teaching research: A creative arts intervention in the classroom. Journal of Nursing Education, 44, 330-333.

Wang, Y., Xie, G., \& Cui, X. (2016). Effects of emotional intelligence and self-leadership on students' coping with stress. Social Behavior and Personality: An International Journal, 44(5), 853-864.

Waters, W. (2015). Coping, positive affect and choices (Ph. D). Spalding University.

Watson, D., \& Walker, L. (1996). The long-term stability and predictive validity of trait measures of affect. Journal of Personality and Social Psychology, 70(3), 567-577.

Watson, D., Clark, L., \& Tellegen, A. (1988). Development and validation of brief measures of positive and negative affect: The PANAS scales. Journal Of Personality And Social Psychology, 54(6), 1063-1070.

Wilkinson, R., \& Chilton, G. (2013). Positive art therapy: Linking positive psychology to art therapy theory, practice, and research. Art Therapy, 30(1), 4-11.

World Health Organization (2018). Adolescent health and development. Retrieved 12 May 2018, 
from http://www.searo.who.int/entity/child_adolescent/topics/adolescent_health/en/

World Health Organization. (2018). Mental health: strengthening our response. Retrieved 1 May 2018, from http://www.who.int/en/news-room/fact-sheets/detail/mental-healthstrengthening-our-response

World health organization. (2011). Mental health atlas 2011. Geneva.

Yap, S. (2015). Parental involvement, self-efficacy beliefs and subjective well-being of adolescents in Kuala Lumpur, Malaysia (Ph. D). Universiti Putra Malaysia.

Yu, C. (2017). A study on college student's experience of participating in Zentangle de-stress group (Master's thesis). Retrieved from National digital library of theses and dissertations in Taiwan.

Zellars, K., Meurs, J., Perrewe, P., Kacmar, C., \& Rossi, A. (2009). Reacting to and recovering from a stressful situation: The negative affectivity-physiological arousal relationship. Journal of Occupational Health Psychology, 14(1), 11-22.

Zeng, X., Chiu, C., Wang, R., Oei, T., \& Leung, F. (2015). The effect of loving-kindness meditation on positive emotions: a meta-analytic review. Frontiers in Psychology, 6.

Zhang, Y., \& Han, B. (2016). Positive affect and mortality risk in older adults: A meta-analysis. Psych Journal, 5(2), 125-138.

Zentangle Uses. (2014). Retrieved from zentangle: https://www.zentangle.com/zentangle-uses 